\title{
Susceptibility of Mefenoxam-Treated Cucurbits to Isolates of Phytophthora capsici Sensitive and Insensitive to Mefenoxam
}

\author{
K. H. Lamour, Department of Entomology and Plant Pathology, The University of Tennessee, Knoxville 37996- \\ 4560, and M. K. Hausbeck, Department of Plant Pathology, Michigan State University, East Lansing 48824-1312
}

\begin{abstract}
Lamour, K. H., and Hausbeck, M. K. 2003. Susceptibility of mefenoxam-treated cucurbits to isolates of Phytophthora capsici sensitive and insensitive to mefenoxam. Plant Dis. 87:920-922.

The susceptibility of mefenoxam-treated cucurbit plants to infection by isolates of Phytophthora capsici that were sensitive (S), intermediately sensitive (IS), and fully insensitive (I) to mefenoxam in vitro was investigated to determine if in vitro screening will accurately predict the response of mefenoxam-treated cucurbit plants to infection by $P$. capsici. Isolates were recovered from a cross between IS parents or from naturally infected cucumbers, squash, pumpkins, and peppers in Michigan, New York, and North Carolina. Pumpkin or yellow squash seedlings were treated with water or mefenoxam at either $19.17 \mu \mathrm{g} / \mathrm{ml}$ or $57.51 \mu \mathrm{g} / \mathrm{ml} 24 \mathrm{~h}$ prior to inoculation. Four days after inoculation, all of the isolates of P. capsici exhibited similarly high virulence on the water-treated seedlings. The diameter of the lesions produced by S, IS, and I isolates on mefenoxam-treated seedlings ranged from no visible lesions for $\mathrm{S}$ isolates to lesions indistinguishable from those produced on water-treated plants for I isolates. These findings are consistent with the expectations based on in vitro screening and suggest that in vitro screening of mefenoxam sensitivity using a single high rate of mefenoxam $(100 \mathrm{ppm})$ provides useful information for predicting the response of natural populations of $P$. capsici to mefenoxam.
\end{abstract}

Root, crown, and fruit rot caused by Phytophthora capsici Leonian causes significant damage to cucurbit hosts in Michigan annually, and in recent years the incidence and severity of disease have increased. There are few resistant cultivars of cucurbits, and cultural, chemical, and rotational strategies often do not provide adequate control when conditions are favorable for disease. P. capsici is heterothallic and requires both $\mathrm{A} 1$ and $\mathrm{A} 2$ compatibility types (CTs) to complete the sexual stage and form thick-walled oospores (4). Phenotypic and molecular evidence suggest that sexual recombination plays an important role in generating genotypic diversity and that oospores persist dormantly in Michigan soils for extended periods of time (6-8). The systemic phenylamide fungicide (PAF) mefenoxam is applied by cucurbit growers in Michigan to protect plants from $P$. capsici. Characterization of the inheritance of mefenoxam sensitivity in $P$. capsici determined by in vitro crosses and comparison of progeny phenotypes to the expectations for Mendelian inheritance indicates that insensitivity is conferred by a single incompletely dominant gene with isolates falling into

Corresponding author: K. H. Lamour

E-mail: klamour@utk.edu

Accepted for publication 17 March 2003.

Publication no. D-2003-0527-01R

(C) 2003 The American Phytopathological Society one of three categories: fully sensitive (S), intermediately sensitive (IS), and fully insensitive (I) (6). The mode of action of the PAFs, using metalaxyl as the representative compound and cultures of $P$. infestans and $P$. megasperma f. sp. medicaginis indicate that metalaxyl specifically inhibits uridine incorporation into RNA (3). Because of the rapidity with which PAF insensitivity has arisen in natural populations of oomycetes (9) and the ease of generating insensitive isolates in vitro $(1,2)$, it is thought that a single mutation is likely to be responsible for generating the insensitivity allele and that insensitivity is highly probable with extended PAF use (4).

Screening $P$. capsici for sensitivity to mefenoxam using amended-agar techniques is a fast and inexpensive tool to characterize variation in natural populations, but it may not accurately predict mefenoxam- $P$. capsici dynamics in planta. Our objective was to test the null hypothesis that in vitro screening adequately predicts the reaction of mefenoxam-treated cucurbits to infection by $P$. capsici isolates designated sensitive, intermediately sensitive, and insensitive to mefenoxam based on amended-agar screening.

\section{MATERIALS AND METHODS}

Cultures of Phytophthora capsici. In experiment 1 , isolates were selected from a cross between isolates $244 \times 216$ and included one sensitive isolate (244216-78), one intermediately sensitive isolate (244216-32), and one insensitive isolate (244216-58). Isolates 244 and 216 were recovered from naturally infected cucumbers in Michigan and are both intermediately sensitive to mefenoxam. The cross was performed by placing 7-mm plugs of each isolate approximately $2 \mathrm{~cm}$ apart on RA (rifampicin $30 \mathrm{ppm}$, ampicillin 150 ppm) amended UCV8 (840 ml distilled water, $163 \mathrm{ml}$ unclarified V8 juice, $3 \mathrm{~g}$ $\mathrm{CaCO}_{3}, 16 \mathrm{~g}$ Bacto agar) plates and incubating in the dark for 3 months at room temperature. Oospores were germinated and individual oospores isolated as previously described (6).

In experiment 2 , eight isolates of $P$. capsici recovered from naturally infected hosts in Michigan, North Carolina, or New York were used (Table 1). Hosts included pumpkin (Cucurbita pepo L.), cucumber ( $\mathrm{Cucu-}$ mis sativus L.), yellow squash (Cucurbita pepo L.), and bell pepper (Capsicum annuum L.). Isolation and generation of single zoospore cultures were accomplished as previously described (6). Three isolates were sensitive, two isolates were intermediately sensitive, and three isolates were insensitive to mefenoxam (Table 1).

Laboratory screening for mefenoxam sensitivity and compatibility type. Single oospore and single zoospore isolates were screened for in vitro response to mefenoxam by placing agar plugs from the edge of actively expanding single oospore colonies at the center of $100 \times 15 \mathrm{~cm}$ UCV8 plates amended with 0 and $100 \mathrm{ppm}$ mefenoxam (Ridomil Gold EC, Novartis, Greensboro, NC, 48\% AI, suspended in sterile distilled water and added to UCV8 agar cooled to $49^{\circ} \mathrm{C}$ ). Two mefenoxamamended and two control plates were inoculated for each isolate per screen. Each screen was conducted twice. Inoculated plates were incubated at 22 to $23^{\circ} \mathrm{C}$ for 3 days and colony diameters measured. Percent growth of an isolate on amended media was calculated by subtracting the inoculation plug diameter $(7 \mathrm{~mm})$ from the diameter of each colony and dividing the average diameter of the amended plates by the average diameter of the unamended control. Isolates were assigned a mefenoxam sensitivity based on the percent growth of the control and were scored as sensitive (S) if growth at $100 \mathrm{ppm}$ was less than $30 \%$ of the control, intermediately sensitive (IS) if growth was between 30 and $90 \%$ of the control, and insensitive (I) if growth was greater than $90 \%$ of the control (6). Compatibility types were assigned by pairing isolates with field isolate OP97 
(A1 compatibility type) and SP98 (A2 compatibility type) on UCV8 plates, incubating the plates at 23 to $25^{\circ} \mathrm{C}$ in the dark for 3 to 6 days, and visually inspecting the plates after 3 days for oospore formation.

Seedling growth and inoculation. Both experiments were conducted in a growth chamber (Controlled Environments Inc., Pembina, ND) that provided $14 \mathrm{~h}$ of light from four $60 \mathrm{~W}$ cool-white fluorescent bulbs and maintained $23.5^{\circ} \mathrm{C}$ night $/ 25.5^{\circ} \mathrm{C}$ day temperatures. Pumpkin (cv. Aspen F1 hybrid) and yellow squash (cv. Seneca prolific) seedlings were used in experiments 1 and 2, respectively. Both hosts are commonly infected by $P$. capsici in Michigan, New York, and North Carolina.

Seedlings with the first true leaf emerging were treated with either mefenoxam or distilled water $24 \mathrm{~h}$ prior to being inoculated with $P$. capsici. Inoculations were made by either placing 7-mm plugs of actively expanding mycelium onto the unwounded surface of the plants at the soil line and gently pushing moist soil against the plug to ensure continuous contact of mycelium with the plant epidermis (experiment 1 ), or by pouring $10 \mathrm{ml}$ of a mycelial slurry at the base of the plant (experiment 2). The mycelial slurry was generated by growing isolates on RAUCV8 media for 3 days before mincing the cultures briefly (three 5-s bursts) using a mixer (Ivan Sorvall Inc., Norwalk, CT). Following inoculation, the soil was kept moist with distilled water.

Pathogen response on mefenoxamtreated seedlings. In experiment 1 , pumpkin seedlings were drenched with $100 \mathrm{ml}$ of distilled water (DW) or with mefenoxam at either $19.17 \mu \mathrm{g} / \mathrm{ml}$ or 57.51 $\mu \mathrm{g} / \mathrm{ml}$ (Ridomil Gold EC, 48.8\% AI) $24 \mathrm{~h}$ prior to inoculation with UCV8 agar plugs with or without the pathogen. The 19.17 $\mu \mathrm{g} / \mathrm{ml}$ treatment corresponds approximately to the rate of application used by some vegetable growers in Michigan, and the $57.51 \mu \mathrm{g} / \mathrm{ml}$ treatment is three times that rate. A third rate of $191.7 \mu \mathrm{g} / \mathrm{ml}(10 \times$ the field rate) was used in preliminary studies, but was not investigated further due to significant stunting of plants compared with untreated controls. In experiment 2, yellow squash seedlings were drenched with $100 \mathrm{ml}$ of either DW or a $57.51 \mu \mathrm{g} / \mathrm{ml}$ solution of mefenoxam $24 \mathrm{~h}$ prior to inoculation with $P$. capsici.

Statistics. In both experiments, the treated plants were arranged in a completely randomized design. Each plant/ inoculum combination was replicated five times within an experiment, and each experiment was conducted twice. Experiments were terminated after 4 days, and the length of acropetal lesion expansion from the point of inoculation was measured. Results were similar between the replicate experiments, and data were combined for statistical analysis. A one-way analysis of variance was performed with PROC GLM of SAS (release 6.12; SAS Institute, Inc., Cary, NC). Lesion size was compared between the water- and mefenoxam-treated plants for each isolate using the least squares means $t$ test.

\section{RESULTS}

In experiments 1 and 2 , the stems of pumpkin and yellow squash plants treated with water and inoculated with $P$. capsici became constricted at the point of inoculation and developed orange-brown lesions extending up from the soil line. Plants treated with mefenoxam and inoculated with sensitive isolates had no visible disease symptoms (Table 2). Mefenoxamtreated plants inoculated with intermediately sensitive isolates had symptoms similar to those observed on the water-treated plants, but the lesions were approximately half the length. There was no difference in the ability of insensitive isolates to infect water-treated or mefenoxam-treated plants (Table 2). In experiment 1 , the intermediately sensitive isolate caused significantly smaller lesions on the pumpkin plants treated with mefenoxam at $57.51 \mu \mathrm{g} / \mathrm{ml}$ than on plants treated at $19.17 \mu \mathrm{g} / \mathrm{ml}(2.08$ $+/-0.09 \mathrm{~cm}$ and $2.57+/-0.14 \mathrm{~cm}$, respectively). There was no difference in the ability of insensitive isolates to infect water-treated or mefenoxam-treated plants.

\section{DISCUSSION}

Hwang and Kim (5) have suggested that in hot peppers a portion of the efficacy of metalaxyl may be due to an increase in the capacity of treated plants to produce the phytoalexin capsidiol. If an analogous phenomena (e.g., mefenoxam stimulates plant defense) were occurring in cucurbits, then it is possible that in vitro screening would not accurately predict the reaction of mefenoxam-treated cucurbit plants to infection by isolates of $P$. capsici deter-

Table 1. Compatibility type and mefenoxam sensitivity for isolates of Phytophthora capsici recovered from naturally infected hosts or from a laboratory cross $(244 \times 216)$ between isolates intermediately sensitive to mefenoxam

\begin{tabular}{lcllr}
\hline Isolate & Host $^{\mathbf{a}}$ & State & $\mathbf{C T}^{\mathbf{b}}$ & MS $^{\mathbf{6}} \mathbf{\%}^{\mathbf{c}}$ \\
\hline 3304BX & Squash & Michigan & A1 & 1 \\
6551GT & Cucumber & Michigan & A2 & 4 \\
6845BAR & Squash & Michigan & A1 & 130 \\
$6611 \mathrm{MM}$ & Pumpkin & New York & A1 & 0 \\
$6607 \mathrm{MM}$ & Pumpkin & New York & A2 & 51 \\
$6618 \mathrm{MM}$ & Pumpkin & New York & A2 & 110 \\
$6339 \mathrm{NC}$ & Pepper & North Carolina & A1 & 53 \\
$6376 \mathrm{NC}$ & Pepper & North Carolina & A2 & 105 \\
$244216-78$ & OP & Michigan & A2 & 1 \\
$244216-32$ & OP & Michigan & A2 & 54 \\
$244216-58$ & OP & Michigan & A2 & 106 \\
\hline
\end{tabular}

${ }^{a} \mathrm{OP}=$ oospore progeny from a cross between parental isolates $(244 \times 216)$ that were intermediately sensitive to mefenoxam.

${ }^{\mathrm{b}} \mathrm{CT}=$ compatibility type.

${ }^{\mathrm{c}} \mathrm{MS}=$ Mefenoxam sensitivity reported as the percentage of growth on V8 agar plates amended with 100 ppm mefenoxam.

Table 2. Length of lesions produced by mefenoxam sensitive (S), intermediately sensitive (IS), and insensitive (I) isolates of Phytophthora capsici on yellow squash seedlings treated with mefenoxam or water

\begin{tabular}{lccc}
\hline $\begin{array}{l}\text { Phytophthora capsici } \\
\text { isolate }\end{array}$ & \multicolumn{3}{c}{ Lesion length $(\mathbf{c m})^{\mathbf{b}}$} \\
\cline { 2 - 4 } & Mefenoxam $\mathbf{( 5 7 . 5 1} \boldsymbol{\mu g} / \mathbf{m l})$ & Water & Difference $^{\mathbf{c}}$ \\
\hline 3304BX(S) & 0 & $3.56 \pm 0.92$ & $3.56^{* *}$ \\
6611MM(S) & 0 & $4.33 \pm 0.82$ & $4.33^{* *}$ \\
6551GT(S) & 0 & $4.29 \pm 0.83$ & $4.29^{* *}$ \\
6339NC(IS) & $1.36 \pm 1.02$ & $4.07 \pm 1.16$ & $2.71^{*}$ \\
6607MM(IS) & $1.77 \pm 1.15$ & $4.64 \pm 1.01$ & $2.87^{*}$ \\
6376NC(I) & $4.79 \pm 1.33$ & $4.75 \pm 1.02$ & $\mathrm{~ns}$ \\
6618MM(I) & $4.29 \pm 1.14$ & $4.51 \pm 1.04$ & $\mathrm{~ns}$ \\
6845BAR(I) & $3.95 \pm 1.61$ & $4.26 \pm 1.21$ & $\mathrm{~ns}$ \\
244216-78(S) & 0 & $5.89 \pm 0.13$ & $5.89^{* *}$ \\
244216-32(IS) & $2.08 \pm 0.09$ & $4.88 \pm 0.11$ & $2.80^{*}$ \\
244216-58(I) & $5.27 \pm 0.15$ & $5.18 \pm 0.13$ & $\mathrm{~ns}$ \\
Null & 0 & 0 & $\mathrm{~ns}$ \\
\hline
\end{tabular}

${ }^{a}$ Mefenoxam sensitivity determined by in vitro screening on $100 \mathrm{ppm} \mathrm{AI}$ amended media in which $\mathrm{S}$ $<30 \%$ growth of control (GC), IS = between 30 and $90 \% \mathrm{GC}$, and I $>90 \% \mathrm{GC}$.

${ }^{b}$ Lesion length $(\mathrm{cm})$ from inoculation point at the soil line. There were 10 replications per treatment. Seedlings were drenched with $100 \mathrm{ml}$ of the mefenoxam suspension or distilled water $24 \mathrm{~h}$ prior to inoculation.

${ }^{\mathrm{c}}$ Difference in lesion length between treated and untreated plants where $* *=$ significant difference at $P=0.01, *=$ significant difference at $P=0.05$, and $\mathrm{ns}=$ no significant difference according to least squares means $t$ test. 
mined to be insensitive through laboratory screening.

In this study, mefenoxam protected pumpkin and yellow squash seedlings from infection by isolates of $P$. capsici determined to be sensitive via in vitro screening, but did not protect against isolates designated intermediately sensitive or insensitive. Lesions on mefenoxam-treated seedlings inoculated with intermediately sensitive isolates were about half the length of lesions on water-treated seedlings, and there was no difference in the size of lesions produced by insensitive isolates on water or mefenoxam-treated plants. These results indicate that the reaction of $P$. capsici to mefenoxam in pumpkin and yellow squash seedlings agrees with the reaction of $P$. capsici to mefenoxam suspended in V8 agar.

In conclusion, it appears that in vitro mefenoxam screening provides a useful assessment of the sensitivity of $P$. capsici to mefenoxam in cucurbits. The ease, relatively low cost, and speed of screening $P$. capsici isolates on mefenoxam-amended agar allow populations of $P$. capsici to be monitored in a timely manner and provide useful information for predicting the response of natural populations of $P$. capsici to mefenoxam.

\section{ACKNOWLEDGMENTS}

This work was funded by the Michigan Agricultural Experiment Station, Michigan State University Extension, Michigan Department of Agriculture, Michigan Farm Bureau (GREEEN cooperative), Pickle and Pepper Research Committee, Pickle Packers International, Inc., and the Pickle Seed Research Fund, Pickle Packers International. We thank M. Bour for laboratory assistance and M. McGrath, C. MacNeil, J. Gibbons, and G. Holmes for assistance in procuring isolates.

\section{LITERATURE CITED}

1. Bower, L. A., and Coffey, M. D. 1985. Development of laboratory tolerance to phosphorus acid, fosetyl-A1, and metalaxyl in Phytophthora capsici. Can. J. Plant Pathol. 7:1-6.

2. Bruin, G. C. A., and Edgington, L. V. 1982. Induction of fungal resistance to metalaxyl by ultraviolet irradiation. Phytopathology 72:476480.

3. Davidse, L. C., van den Berg-Velthuis, G. C.
M., Mantel, B. C., and Jespers, A. B. K. 1991. Phenylamides and Phytophthora. 349-360 in Phytophthora. J. A. Lucas, R. C. Shattock, D. S. Shaw, and L. R. Cooke, eds. British Mycological Society, Cambridge.

4. Erwin, D. C., and Ribeiro, O. K. 1996. Phytophthora Diseases Worldwide. American Phytopathological Society, St. Paul, MN.

5. Hwang, B. K., and Kim, C. H. 1995. Phytophthora blight of pepper and its control in Korea. Plant Dis. 79:221-227.

6. Lamour, K. H., and Hausbeck, M. K. 2000 Mefenoxam insensitivity and the sexual stage of Phytophthora capsici in Michigan cucurbit fields. Phytopathology 90:396-400.

7. Lamour, K. H., and Hausbeck, M. K. 2001. The dynamics of mefenoxam insensitivity in a recombining population of Phytophthora capsici characterized with amplified fragment length polymorphism markers. Phytopathology 91:553-557.

8. Lamour, K. H., and Hausbeck, M. K. 2001. Investigating the spatiotemporal genetic structure of Phytophthora capsici in Michigan. Phytopathology 91:973-980.

9. Parra, G., and Ristaino, J. 1998. Insensitivity to Ridomil Gold (mefenoxam) found among field isolates of Phytophthora capsici causing Phytophthora blight on bell pepper in North Carolina and New Jersey. Plant Dis. 82:711. 